\title{
DEVELOPMENT OF PH-BASED ELECFET BIOSENSORS \\ FOR LACTATE ION DETECTION
}

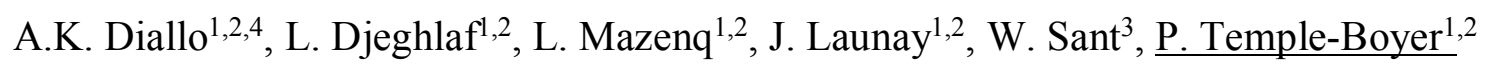

${ }^{1}$ CNRS, LAAS, 7 avenue du colonel Roche, F-31400 Toulouse, France

${ }^{2}$ University de Toulouse, UPS, LAAS, F-31400 Toulouse, France

${ }^{3}$ HEMODIA, rue du chêne vert, F-31682 Labège, France

${ }^{4}$ Laboratoire de Chimie et Physique des Matériaux (LCPM), Université de Ziguinchor, Senegal

\begin{abstract}
In this work, we report on ElecFET (Electrochemical Field Effect Transistor) devices potentially of interest for the detection of different molecules in solution. ElecFET are electrochemical microsensors in liquid phase, based on two elements: (i) a pH-sensitive chemical field effect transistor ( $\mathrm{pH}-\mathrm{ChemFET}$ ) and (ii) a metallic microelectrode deposited around the sensitive gate. The coexistence of these two elements combines (i) potentiometric and (ii) amperometric detection effects at the microscale. Design, fabrication and experimental validation of ElecFETs based on silicon and polymer micro-technologies, are reported. We first demonstrate the detection of hydrogen peroxide $\left(\mathrm{H}_{2} \mathrm{O}_{2}\right)$ in solution, showing a sensitivity of $5 \mathrm{mV} / \mathrm{mM}$ in the $[10$ $100 \mathrm{mM}]$ concentration range. The ElecFET concept is then extended to the detection of glucose and lactate in the $[1-30 \mathrm{mM}]$ and $[1-6 \mathrm{mM}]$ concentration range respectively. The sensitivities are between 2-6 $\mathrm{mV} / \mathrm{mM}$ and $8-20 \mathrm{mV} / \mathrm{mM}$ respectively.
\end{abstract}

Keywords: electrochemical sensor, ChemFET, microelectrode, hydrogen peroxide, glucose, lactate, potentiometric detection 



\section{Introduction}

The monitoring of L-lactate biosensors is gaining interest for clinical use [1-3] and food quality [4] assessment. Lactate ion analysis in saliva can be used as a diagnostic tool for cystic fibrosis. It can also be used for monitoring lactate concentrations in athletes (i.e. $400 \mathrm{~m}$ runners) during and after a training session, in order to estimate their capability to quickly metabolize lactic acid, and thus evaluate effectiveness of the training program. Furthermore, the food quality monitoring requires suitable analytical methods for process and quality control, methods that will be rapid, reliable, specific and cost-effective.

Lactate oxidase (LOD) is widely used for lactate detection because of its simple reaction; LOD catalyzes the lactate oxidation to pyruvate and hydrogen peroxide $\left(\mathrm{H}_{2} \mathrm{O}_{2}\right)$. In most of the publications, lactate detection is based on the amperometric technique, which employs microelectrodes for the monitoring oxido-reduction reactions at a conductive solid/liquid interface [5-8]. This technique faces a severe technological issue. As the microelectrodes size becomes significantly lower than the diffusion length, spherical (rather than linear) diffusion phenomena occur at the microelectrode surface. As an effect, the related amperometric response is no longer time-dependent. Another technique used to measure the electrochemical potential at an insulative solid/liquid interface is potentiometry. The potentiometry technique is based on chemical field effect transistors (ChemFET) [9-11]. ChemFETs attracted attention in the development of biosensors, and were extended to enzyme field-effect transistors (EnFET). EnFETs are based on $\mathrm{pH}$-dependent biocatalytic reactions leading to charge modification at the gate surface, according to the substrate concentration. Several EnFETs based on a variety of enzymes [9] such as glucoseoxidase (GOD) [12-14], horseradish peroxidase [15] urease [16], lactate dehydrogenase [17, 18], have been reported so far. For example, Xu et al. have reported a ChemFET-based lactate biosensor based on the LOD functionalization on the sensitive gate [19]. The authors immobilized lactate oxidase and $\mathrm{MnO}_{2}$ nanoparticles in poly(dimethyldiallylammonium chloride) (PDDA) films via 
layer-by-layer self-assembly to construct $\left(\mathrm{PDDA} / \mathrm{MnO}_{2} / \mathrm{PDDA} / \mathrm{LOD}\right)_{\mathrm{n}}$ multilayer films. $\mathrm{MnO}_{2}$ powder acts as a catalyst to stimulate the disproportionation of $\mathrm{H}_{2} \mathrm{O}_{2}$ to $\mathrm{O}_{2}$ and $\mathrm{H}_{2} \mathrm{O}$. $\mathrm{MnO}_{2}$ nanoparticles react with hydrogen peroxide to form $\mathrm{Mn}^{2+}$ and $\mathrm{O}_{2}$, with two hydrogen ions $\mathrm{H}_{3} \mathrm{O}^{+}$ consumption.

The combination of amperometric and potentiometric techniques is a promising method for lactate detection. The concept involves the functional integration of a microelectrode with a ChemFET on a single chip [20-22]. Such a device is indicated as an electrochemical field effect transistor (ElecFET). By combining these two transduction principles at the microscale, the ElecFET technology provides new electrochemical detection potentialities. First, it enables the adaptation of the $\mathrm{pH}$-ChemFET-based potentiometric principles to the detection of electro-active chemical species and, as a consequence, their extension to new enzymatic family such as oxidases (production of hydrogen peroxide $\mathrm{H}_{2} \mathrm{O}_{2}$ ). Second, it allows electrochemical measurement in liquid phase without any current monitoring at very low level (nano- or pico-amoperes), whose control is still a challenge in term of drift and signal to noise ratio. Finally, it is compatible with the siliconbased technology and can be still improved thanks to further technological integration.

In this paper, we report on design, fabrication and study of ElecFET microdevices, which combine potentiometric and amperometric detection/transduction principles at the microscale, thanks to the common integration of a metallic microelectrode with a $\mathrm{pH}$-sensitive ChemFET. First we apply this concept to the detection of $\mathrm{H}_{2} \mathrm{O}_{2}$ by studying the influences of the main polarization parameters, i.e. voltage $\left(V_{P}\right)$ and duration (tP) onto the platinum microelectrode. Then, we focus on the detection of glucose by functionalizing the gate surface of the transistor with an enzymatic layer containing glucose oxidase, and finally extended to the lactate detection, with a lactate oxidase enzyme immobilization.

\section{Experimental}


$\mathrm{N}$-channel, $\mathrm{SiO}_{2} / \mathrm{Si}_{3} \mathrm{~N}_{4}$-gate, $\mathrm{pH}$-sensitive chemical field effect transistors (pH-ChemFET) were fabricated on (100)-oriented N-type (500 $\Omega . \mathrm{cm})$ silicon wafers using a standard P-well technology. Such technology was studied in previous work, evidencing threshold voltage $\mathrm{V}_{\mathrm{t}}$ around $0.7 \mathrm{~V}$ and low leakage current $\left(\mathrm{I}_{\mathrm{off}}<1 \mu \mathrm{A}\right)$ [23]. Then, a tantalum/platinum (thickness: 50nm / 200nm) layer was deposited by physical vapor deposition and patterned by lift-off process in order to integrate the microelectrode all around the $\mathrm{pH}$-ChemFET sensitive gate (mean distance: $100 \mu \mathrm{m}$ ). Finally, a SU-8 passivation was performed at the wafer level, leaving the $\mathrm{pH}$-ChemFET sensitive surface and the Ta/Pt microelectrode active area uncovered. All the technological processes (figure 1a) were developed in cleanroom (class 10000 and 100). The ElecFET microdevices were manufactured on $3.5 \times 3.5 \mathrm{~mm}^{2}$ chips. These chips were stuck on specifically coated printed circuit using an epoxy insulating glue. After wire bonding, packaging was finally performed at the system level using a silicone glop-top in order to adapt the final sensor to the detection in liquid phase (figure 1b).

ElecFET detection/transduction principles were first studied for the hydrogen peroxide $\mathrm{H}_{2} \mathrm{O}_{2}$ detection in phosphate buffer (PBS, $\mathrm{pH}=7.2)$ solutions $(\sim 20 \mathrm{~mL})$ containing different stabilized concentrations $\left[\mathrm{H}_{2} \mathrm{O}_{2}\right]$ ranging from 10 to $100 \mathrm{mM}$. Then, enzymatic functionalization process and the ElecFET enzymatic detection properties were tested for the glucose detection using glucose oxidase because of their properties in terms of activity, stability and cost. At last, when the whole protocol was optimized, the lactate detection was investigated using lactate oxidase. The enzymatic membranes (GOD: G6125-10kU and LOD: L0638-50U purchased from SIGMA) were prepared by the cross-linking of enzymes with bovine serum albumin (BSA) in glutaraldehyde solution (5\%). A mixture of $50 \mu \mathrm{L}$ of enzyme solution $(0.5 \mathrm{mg}$ of protein) with $0.5 \mathrm{mg}$ of BSA was prepared in 100 $\mathrm{mM}$ phosphate buffer $\mathrm{pH} 7.2$ with $5 \mu \mathrm{L}$ of glycerol added into the mixture. Glycerol was used as a plasticizer to avoid the formation of cracks in the enzyme membrane during storage and to result in a better homogeneity of the membrane and its adhesion on the surface of the microsensor. $0.3 \mu \mathrm{L}$ of 
the enzymatic solution were deposited on the sensitive area using a micropipette then, $0.6 \mu \mathrm{L}$ of glutaraldehyde (5\%) were dropped onto the enzyme layer and left to dry for 60 minutes in air. The microsensor was then stored at $4{ }^{\circ} \mathrm{C}$ overnight.

All experiments were performed in ambient atmosphere at room temperature according to a specific electrical scheme (figure 1a). The different electrical operations in solution were performed with a commercial reference calomel electrode in order to bias the electrolyte to the mass $\left(\mathrm{V}_{\mathrm{GRE}}=\right.$ $\mathrm{V}_{\text {electrolyte }}=0$ ). A suitable electrical polarization (potential $\mathrm{V}_{\mathrm{p}}$, time $\mathrm{t}_{\mathrm{p}}$ ) was applied to the $\mathrm{Ta} / \mathrm{Pt}$ microelectrode using a Keithley 2400 voltage source in order to trigger specific oxido-reduction phenomena. The $\mathrm{pH}-\mathrm{ChemFET}$ characterization was performed in saturation mode while using constant drain-source voltage $\mathrm{V}_{D S}$ and drain-source current IDS (typically $\mathrm{V}_{D S}=1 \mathrm{~V}$ and IDS $=0.1$ $\mathrm{mA}$ ). A ChemFET-meter measurement interface was used to measure the pH-ChemFET gatesource voltage $\mathrm{V}_{\mathrm{GS}}$, also called output voltage $\mathrm{V}_{\text {out}}$, enabling the local $\mathrm{pH}$ monitoring in the microelectrode surroundings depending on the polarization conditions.

\section{Results and discussion}

3.1. Hydrogen peroxide detection

The ElecFET concept was initially used for the detection of hydrogen peroxide $\mathrm{H}_{2} \mathrm{O}_{2}$ oxidation in water-based solutions:

- $\mathrm{H}_{2} \mathrm{O}_{2}$ oxidation $\left(\mathrm{V}_{\mathrm{P}}>\mathrm{E}_{1+}\right): \mathrm{H}_{2} \mathrm{O}_{2}+2 \mathrm{H}_{2} \mathrm{O}---->\mathrm{O}_{2}+2 \mathrm{H}_{3} \mathrm{O}^{+}+2 \mathrm{e}^{-}$

where $\mathrm{E}_{1+}$ is the equilibrium potential of the $\mathrm{O}_{2} / \mathrm{H}_{2} \mathrm{O}_{2}$ redox couple.

In the presence of hydrogen peroxide $\mathrm{H}_{2} \mathrm{O}_{2}$, a positive bias on the platinum microelectrode produces hydronium $\mathrm{H}_{3} \mathrm{O}^{+}$ions. Therefore the local $\mathrm{pH}$ decreases and finally the $\mathrm{pH}-\mathrm{ChemFET}$ - 
meter output voltage $\mathrm{V}_{\text {out }}$ increases. Since the $\mathrm{E}_{1+}$ is $\sim 0.7 \mathrm{~V}[24]$, a similar polarization voltage $\mathrm{VP}_{\mathrm{P}}$ was applied on the platinum microelectrode at different polarization times (tP) while maintaining a constant $\left[\mathrm{H}_{2} \mathrm{O}_{2}\right]$ concentration at $50 \mathrm{mM}$ in the analyzed buffer solution $(\mathrm{pH}=7.2)$. Positive shifts of $\mathrm{V}_{\text {out }}$ (i.e. local $\mathrm{pH}$ decreases) are clearly evidenced with the $50 \mathrm{mmol} / \mathrm{L} \mathrm{H}_{2} \mathrm{O}_{2}$ concentration in solution, in agreement with equation 1 (figure $2 a) . V_{\max }$ (maximum $V_{\text {out }}$ ) increases with tp, and the voltage variation $\Delta \mathrm{V}_{\text {out }}$ reaches $\sim 150 \mathrm{mV}(\Delta \mathrm{pH} \approx 3$ according to the $\mathrm{pH}$-ChemFET sensitivity around $50 \mathrm{mV} / \mathrm{pH})$ for the highest polarization time $\left(\mathrm{tp}_{\mathrm{P}}=60 \mathrm{~s}\right)$.

The influence of the polarization voltage $V_{P}$ was also studied (figure $2 b$ ). Starting from $V_{P}=$ $0.5 \mathrm{~V}$ (lower than the $\mathrm{H}_{2} \mathrm{O}_{2} / \mathrm{O}_{2}$ equilibrium potential $\mathrm{E}_{1+}$ [20]) impulsional voltage variations (i.e. impulsional $\mathrm{pH}$ variations) are probed in the buffered solution: $\mathrm{V}_{\max }$ increases with $\mathrm{V}_{\mathrm{P}}$. However, in the $\mathrm{H}_{2} \mathrm{O}_{2}$ electrolysis case, a constant level $\left(\Delta \mathrm{V}_{\text {out }} \approx 225 \mathrm{mV}\right.$ or $\Delta \mathrm{pH} \approx 4.5$ according to the $\mathrm{pH}$ ChemFET sensitivity) appears in the $[1.1-1.3 \mathrm{~V}]$ polarization voltage range. This level can be easily explained. According to the Buttler-Volmer theory applied to the $\mathrm{H}_{2} \mathrm{O}_{2}$ oxidation, the anodic current depends on the $\left[\mathrm{H}_{2} \mathrm{O}_{2}\right]$ concentration in solution [24]:

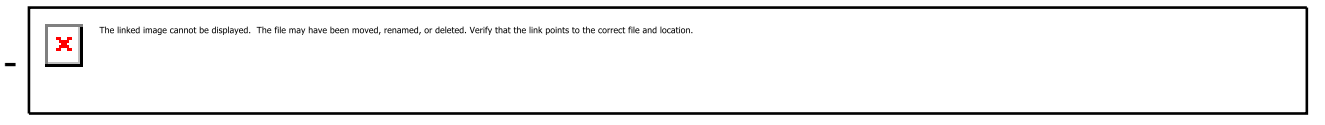

where $\mathrm{E}_{1+}$ is the equilibrium potential of the $\mathrm{O}_{2} / \mathrm{H}_{2} \mathrm{O}_{2}$ redox couple, $\mathrm{F}$ is the Faraday constant, $\mathrm{S}$ is the microelectrode active surface, $\mathrm{k}_{1+}$ and $\alpha_{1+}$ are the standard rate constant and the anodic transfer coefficient of the $\mathrm{O}_{2} / \mathrm{H}_{2} \mathrm{O}_{2}$ redox couple respectively, $\mathrm{R}$ is the ideal gas constant and $\mathrm{T}$ is the temperature.

Since hydrogen peroxide is consumed by the electrochemical reaction (equation 2), the $\left[\mathrm{H}_{2} \mathrm{O}_{2}\right]$ concentration at the microelectrode surface decreases with time until equilibrium is reached between the $\mathrm{H}_{2} \mathrm{O}_{2}$ oxidation (equation 2) and the $\mathrm{H}_{2} \mathrm{O}_{2}$-related diffusion phenomena. This selflimited equilibrium is finally responsible for the constant level phenomenon. Finally, for $\mathrm{V}_{\mathrm{P}}>1.3 \mathrm{~V}$, $\mathrm{H}_{2} \mathrm{O}$ oxidation starts to occur at the microelectrode and interferes with the $\mathrm{H}_{2} \mathrm{O}_{2}$ oxidation (equation 2), leading to a further increase of $V_{\max }$. 
The ElecFET responses obtained with and without hydrogen peroxide were studied and compared (figure $2 \mathrm{~b}$ inset). Therefore ElecFET devices can be used for the potentiometric detection of hydrogen peroxide $\mathrm{H}_{2} \mathrm{O}_{2}$ in solution. The polarization voltage $\mathrm{VP}$ must range between $0.5 \mathrm{~V}$ and $1.3 \mathrm{~V}$ to prevent any water electrolysis interferences. The increase of $\mathrm{V}_{\mathrm{P}}$ is responsible for a sensitivity increase and for a detection range decrease. A compromise was found by choosing the following parameters for our detection experiments: $V_{P}=0.7 \mathrm{~V}$ and $t_{P}=30 \mathrm{~s}$. Different buffered solutions $(\mathrm{pH}=7.2)$ with various hydrogen peroxide $\mathrm{H}_{2} \mathrm{O}_{2}$ concentrations were studied using ElecFET microdevices (figure 3). Results demonstrate that the amplitude of the impulsional voltage variations increases with the $\left[\mathrm{H}_{2} \mathrm{O}_{2}\right]$ concentration in solution, and saturates for the highest values. This saturation phenomenon is related to the previously discussed ElecFET detection principles. When the $\left[\mathrm{H}_{2} \mathrm{O}_{2}\right]$ concentration increases, the $\mathrm{H}_{3} \mathrm{O}^{+}$ions production also increases (equations 1 and 2). Nevertheless, the $\mathrm{H}_{3} \mathrm{O}^{+}$ion increase is limited by diffusion and electromigration phenomena and by the buffer properties, leading to a new chemical equilibrium at the microscale. Hydrogen peroxide $\mathrm{H}_{2} \mathrm{O}_{2}$ potentiometric detection was finally demonstrated in the $[10-100 \mathrm{mM}]$ range with a global sensitivity of $\sim 2 \mathrm{mV} / \mathrm{mM}$ (figure 3 inset).

\subsection{Glucose and lactate detection}

To adapt ElecFET microdevices to bio-electrochemical detection, we used an enzymatic functionalization based on glucose oxidase (GOD) and lactate oxidase (LOD). LOD was preferred to lactate dehydrogenase ( $\mathrm{LDH})$ since it does not require the $\mathrm{NADH} / \mathrm{NAD}^{+}$cofactor in solution to be effective. The biosensor using $\mathrm{LDH}$ has some drawbacks, including the fact that they are unstable, use an additional intermediate reaction and the electrochemical oxidation of NADH occur, generally, at high over potentials [25-27]. GOD and LOD catalyze the conversion of glucose and lactate to gluconic acid and pyruvic acid respectively. The catalysis produces also hydrogen peroxide, which can be oxidized at the microelectrode surface, according to the following reactions: 


$$
\begin{aligned}
& \text { Glucose }+\mathrm{O}_{2}---->\text { Gluconic acid }+\mathrm{H}_{2} \mathrm{O}_{2} \\
& \text { L-lactate }+\mathrm{O}_{2} \text {----> pyruvic acid }+\mathrm{H}_{2} \mathrm{O}_{2}
\end{aligned}
$$

Since the dissociation constants of acids produced by the reactions are very low, a simple $\mathrm{pH}-\mathrm{ChemFET}$ would not significantly detect any changes in term of $\mathrm{pH}$. Thus we exploited the electrochemical technique to achieve the target. The produced hydrogen peroxide was electrochemically oxidized as shown in Equation 1. Their associated reaction kinetics is rapid and is sustained over time through the polarization time. The production of hydronium ions $\mathrm{H}_{3} \mathrm{O}^{+}$remains higher and the $\mathrm{pH}$ may be measured by $\mathrm{pH}$-ChemFET-metry at the microscale.

Figures $4 \mathrm{a}$ and $4 \mathrm{~b}$ show the output voltage variations $\Delta \mathrm{V}_{\text {out }}$ versus time for different lactate and glucose concentrations respectively and for different concentrations of phosphate buffer solution $\left(\mathrm{V}_{\mathrm{P}}=0.7 \mathrm{~V}\right.$ and $\left.\mathrm{t}_{\mathrm{P}}=5 \mathrm{~min}\right)$. When the lactate (respectively glucose) concentration increases, the $\Delta \mathrm{V}_{\text {out }}$ value also increases. In fact, the lactate (respectively glucose) reaction in the presence of LOD (respectively GOD) produced hydrogen peroxide $\mathrm{H}_{2} \mathrm{O}_{2}$. For a potential $\mathrm{V}_{\mathrm{P}}=0.7$ $\mathrm{V}$, the electrochemical molecule was oxidized on the platinum microelectrode, leading to hydronium ions $\mathrm{H}_{3} \mathrm{O}^{+}$release and therefore to a local $\mathrm{pH}$ change measured by the $\mathrm{pH}-\mathrm{ChemFET}$. As soon as the polarization on the platinum microelectrode was interrupted, the ElecFET microsensor response tends to turn to back equilibrium because of diffusion phenomenon and solution buffer effect.

Plotting the maximal $\Delta \mathrm{V}_{\text {out }}$ value versus lactate and glucose concentrations, typical detection curves were obtained for different buffered concentrations, i.e. 6 and $25 \mathrm{mM}$ for the lactate detection, 25 and $100 \mathrm{mM}$ for the glucose detection (figures $5 \mathrm{a}$ and $5 \mathrm{~b}$ ). It appears that the sensitivity of the sensor depends on the buffer concentration, which is a classical result in $\mathrm{pH}-$ ChemFET-metry. However, results enable to determine detection sensitivities between 8 and 20 $\mathrm{mV} / \mathrm{mM}$ for the lactate detection between 2 and $6 \mathrm{mV} / \mathrm{mM}$ for the glucose one, in concentration 
range between [1-6 $\mathrm{mM}]$ and [1-30 $\mathrm{mM}]$ respectively. For lactate detection, ElecFET microsensors give higher sensitivity and lower detection range sensitivity than classical ChemFET-based ones (reported value around $10 \mathrm{mV} / \mathrm{mM}$ in the [1-5 mM] concentration range) [19]. On the contrary, for glucose detection ElecFET are characterized by lower sensitivity on similar detection range [14,21]. Such results discrepancy is related to differences between the LOD-based and GOD-based enzymatic layers. Indeed, experiments were performed according to enzymes initial conditioning and properties, leading to different enzymatic activities and finally to different detection sensitivities and different detection range according to different buffer effects. Detection limit was finally estimated around $0.05 \mathrm{mM}$ for both lactate and glucose detection. Such result is worse than that obtained for conventional amperometry technique [28-30]. Nevertheless, the ElecFET detection properties can be improved by optimizing the enzymatic layer properties, the microdevice geometry and integration level, as well as the polarization conditions.

Finally, the evolution of ElecFET response was studied as a function of polarization time tp for lactate and glucose detection. Figure 6 a was obtained for $1 \mathrm{mM}$ of lactate in different phosphate buffers concentrations, i.e. $6 \mathrm{mM}$ and $25 \mathrm{mM}$, with a polarization voltage $\mathrm{V}_{\mathrm{P}}=0.7 \mathrm{~V}$. The variations of $\Delta \mathrm{V}$ were $20 \mathrm{mV}$ and $135 \mathrm{mV}$ respectively. Figure $6 \mathrm{~b}$ shows the glucose ElecFET response under the same conditions for two different phosphate buffer concentrations, i.e. $25 \mathrm{mM}$ and $100 \mathrm{mM}$. In both cases, the sensor response increases linearly with the polarization time tp and reaches a saturation value. The sensor response was even more pronounced when the buffer concentration decreased. When the polarization time was continuously increased, reactions 1,3 , and 4 increased the concentration of hydronium ions $\mathrm{H}_{3} \mathrm{O}^{+}$and consequently the decrease of the local $\mathrm{pH}$. This behaviour was kept until equilibrium was established between the $\mathrm{H}_{3} \mathrm{O}^{+}$ions production, the diffusion phenomena and the buffer effect.

\section{Conclusion}


To summarize, we studied a promising detection concept named ElecFET microsensor, which uses a $\mathrm{pH}$ ChemFET with a platinum microelectrode and combines potentiometric and amperometric techniques. This new concept was first applied to the detection of $\mathrm{H}_{2} \mathrm{O}_{2}$. The polarization duration tP and voltage $V_{P}$ parameters were studied and the limit of the microelectrode polarization was determined to avoid any interference with the water oxidation reaction. A sensitivity of $5 \mathrm{mV} / \mathrm{mM}$ was obtained in a concentration range of hydrogen peroxide ranging from 10 to $100 \mathrm{mM}$ ]. The detection of $\mathrm{H}_{2} \mathrm{O}_{2}$ opens new opportunities for the $\mathrm{H}_{2} \mathrm{O}_{2}$-based enzymatic detection of biomolecules. This concept was finally applied to the lactate and glucose detection by functionalizing the gate surface with specific enzymes (lactate oxidase and glucose oxidase). Depending on the phosphate buffer concentration, lactate sensitivities between 8 and $20 \mathrm{mV} / \mathrm{mM}$ were evidenced in the $[1-6 \mathrm{mM}]$ concentration range.

\section{Acknowledgements}

This work was funded by the French national research agency ANR-CSOSG (Agence Nationale de la Recherche - Concept, systèmes et Outils pour la Sécurité Globale) in the frame of the SWEAT project ANR-08-SECU-010-01. Finally, the authors thank Dr Samuele Lilliu for helpful discussions.

\section{References}

[1] T. Belli, M. A. Ackermann, L. F. Ribeiro, R. Langeani, R. Galdino da Silva and V. Baldissera, Diabetes Research and Clinical Practice, vol. 76 (2007) pp. 18-23.

[2] L. Metz, P. Sirvent, G. Py, J. F. Brun, C. Fedou, E. Raynaud and J. Mercier, Metabolism, vol. 54 (2005) pp. 1102-1107.

[3] J. Bakker, P. Gris, M. Coffernils, R.J. Kahn and J.L. Vincent, American Journal of Surgery, vol. 171 (1996) pp.221-226. 
[4] T. Rinken and H. Riik, Journal of Biochemical Biophysical Methods, vol. 66 (2006) pp.13-21.

[5] N.G. Patel, A. Erlenkötter, K. Cammann and G.-C. Chemnitius, Sensors and Actuators B, vol. 67 (2000) pp. 134-141

[6] D. Pfeiffer, B. Möller, N. Klimes, J. Szeponik and S .Fischer, Biosensors and Bioelectronics, vol. 12 (1997) pp. 539-550.

[7] N. Ito, S. Miyamoto, J. Kimura and I. Karube, Biosensors and Bioelectronics, vol. 11 (1996) pp. $119-126$.

[8] N. Nikolaus and B. Strehlitz, Microchimica Acta, vol. 160 (2008) pp.15-55.

[9] M.J. Schöning and A. Poghossian: Analyst, vol. 127 (2002) pp. 1137-1151.

[10] P. Bergveld, Sensors and Actuators B, vol. 88 (2003) pp. 1-20.

[11] A. Poghossian, S. Ingebrandt, A. Offenhäusser and M.J. Schöning, Seminars in cell \& developmental biology, vol. 20 (2009) pp. 41-48.

[12] L.Yin, J. Chou, W. Chung, T. Sun, K. Hsiung and S. Hsiung, Sensors and Actuators B, vol. 76 (2001) pp. 187-192.

[13] A. Kharitonov, J. Wasserman, E. Katz, and I. Willner, Journal of Physical Chemistry B, vol. 105 (2001) pp.4205-4213.

[14] X. Luo, J. Xu, W. Zhao and H. Chen, Sensors and Actuators B, vol. 97 (2004) pp. 249-255

[15] V. Volotovsky and N. Kim, Biosensors \& Bioelectronics, vol. 13 (1998) pp.1029-1033

[16] W. Sant, P. Temple-Boyer, E.Chanié, J. Launay and A. Martinez, Sensors and Actuators B, vol. 160 (2011) pp. 59-64.

[17] S.P. Pogorelova, M. Zayats, A. B. Kharitonov, E. Katz and I.Willner, Sensors and Actuators B, vol. 89 (2003) pp.40-47.

[18] M. Zayats, A. B. Kharitonov, E. Katz, A. F. Buckmann and I. Willner, Biosensors and Bioelectronics, vol. 15 (2000) pp. 671-680

[19] J. Xu, W. Zhao, X. Luo and H. Chen, Chemical Communications, DOI: 10.1039/B416548A (2005) pp.792-794. 
[20] B-K. Sohn and C.S. Kim, Sensors and Actuators B, vol. 34 (1996) pp. 435-440.

[21] H.I. Seo, C-S. Kim, B-K. Sohn, T. Yeow, M-T. Son and M. Haskard, Sensors and Actuators B, vol. 40 (1997) pp. 1-5.

[22] B-K. Sohn, B-W. Cho, C-S. Kim and D-H. Kwon, Sensors and Actuators B, vol. 41 (1997) pp. $7-11$.

[23] P. Temple-Boyer, J. Launay, I. Humenyuk, T. Do Conto, A. Martinez, C. Bériet and A. Grisel, Microelectronics Reliability, 44 (2004) pp. 443-447.

[24] A.J. Bard and L.R. Faulkner: "Electrochemical methods: fundamental and applications, second edition", New York: John Wileys \& Sons Inc. (2001).

[25] A.C. Pereira, M.R. Aguiar, A. Kisner, D.V. Macedo, L. T. Kubota, Sensors and Actuators B, vol. 124 (2007) pp. 269-276.

[26] M.J.F. Rebelo, D. Compaguone, G.G. Guilbault, Analytical Letters, vol. 27 (1994) pp. 30273037.

[27] A.S. Santos, L. Gorton, L.T. Kubota, Electrochimica Acta, vol. 47 (2002) pp. 3351-3360.

[28] J. M. Goran, J. L. Lyon, K. J. Stevenson, Analytical Chemistry, vol. 83 (2011) pp. 8123-8129.

[29] G. Aydin, S.S. Çelebi, H. Özyörük, A. Yildiz, Sensors and Actuators B, vol. 87 (2002) pp. 812.

[30] L.V. Shkotova, T.B. Goriushkina, C. Tran-Minh, J.M. Chovelon, A.P. Soldatkin, S.V. Dzyadevych, Materials Science Engineering C, vol. 28 (2008) pp. 943-948.

\section{Biographies}

Abdou Karim Diallo was born on April 14, 1977. He received his Master's Degree in Microelectronics from the Université Louis Pasteur de Strasbourg (France) in 2005. He joined the Institut des Nanotechnologies de Lyon (France) in 2005 and received the $\mathrm{PhD}$ degree from the Ecole Centrale de Lyon in 2008. He was a postdoctoral fellow at the Université de la Méditerranée 
(France) in the Centre Interdisciplinaire des Nanosciences de Marseille (France) where he worked on organic transistor devices in 2009, and joined the French Centre National de la Recherche Scientifique (LAAS-CNRS) as a postdoctoral fellow in 2010. He is working on the development of ChemFET-based microsensors for chemical and biochemical detections.

Lyes Djeghlaf was born on October 5, 1982. He received his Master's Degree in microelectronics from the Université Paul Sabatier de Toulouse (France) in 2009. Then, he joined the Laboratoire d'Architecture et d'Analyse des Systèmes of the French Centre National de la Recherche Scientifique (LAAS-CNRS) as a $\mathrm{PhD}$. He is working on the development of ChemFET-based microsensors for chemical and biochemical detections.

Laurent Mazenq was born on May 30, 1982. He received his University Institute of Technology's Degree from the University Paul Sabatier de Toulouse (France) in 2002. Then, he joined the Laboratoire d'Analyse et d'Architecture des Systèmes of the French Centre National de la Recherche Scientifique (LAAS-CNRS) as an engineer in micro/nanotechnologies. He is more especially working on the development of optical microlithography processes for the technological realisation of micro/nanodevices.

Jérôme Launay was born on March 11, 1975. He received the degree in electronic engineering from the Institut National des Sciences Appliquées de Toulouse" (France) in 1998. He joined the Laboratoire d'Architecture et d'Analyse des Systèmes from the French "Centre National de la Recherche Scientifique" (LAAS-CNRS) in 1998 and received the $\mathrm{PhD}$ degree from the Institut National des Sciences Appliquées de Toulouse (France) in 2001. In 2002, he became lecturer at the Université Paul Sabatier de Toulouse (France). His research activities include the development of chemical microsensors for the detection in liquid phase. 
William Sant was born on May 18, 1969. He received his Master's Degree in electronics in 1996 and his Diplome d'Etudes Approfondies in Microelectronics from the Université Paul Sabatier de Toulouse (France) in 1999. He joined the Laboratoire d'Architecture et d'Analyse des Systèmes of the French Centre National de la Recherche Scientifique (LAAS-CNRS) in 2000 and received the $\mathrm{PhD}$ degree from the Université Paul Sabatier de Toulouse (France) in 2004. Since then, he has joined the HEMODIA society (France) as an R\&D engineer and has been working on the development of ChemFET microsensors for medical applications.

Pierre Temple-Boyer was born on October 25, 1966. He received his Engineer Degree in electronic engineering from the Ecole Supérieure d'Electricité (Paris - France) in 1990 and his Master's Degree in microelectronics from the Université Paul Sabatier de Toulouse (France) in 1992. He joined the Laboratoire d'Architecture et d'Analyse des Systèmes of the French Centre National de la Recherche Scientifique (LAAS-CNRS) in 1992 and received the $\mathrm{PhD}$ degree from the Institut National des Sciences Appliquées de Toulouse (France) in 1995. Since then, as a senior CNRS researcher, he has been working on the development of microtechnologies for the realisation of integrated microsystems. 


\section{Figures Caption}

Figure 1: Cross-section (a) and details (b) of the ElecFET device (chip size: 3.5 x $3.5 \mathrm{~mm}^{2}$ ).

Figure 2: Detection of impulsional $\mathrm{pH}$ variations due to the $\mathrm{H}_{2} \mathrm{O}_{2}$ electrolysis $\left(\left[\mathrm{H}_{2} \mathrm{O}_{2}\right]=50 \mathrm{mM}\right)$ in $100 \mathrm{mM}$ phosphate buffer solutions, influence of the polarization time tp (a) and influence of the polarization voltage $V_{P}$ with and without hydrogen peroxide ( $\mathrm{b}$ and inset)

Figure 3: Detection of impulsional $\mathrm{pH}$ variations related to the $\mathrm{H}_{2} \mathrm{O}_{2}$ electrolysis in phosphate buffer solutions: influence of the $\mathrm{H}_{2} \mathrm{O}_{2}$ concentration and (inset) ElecFET response for the $\mathrm{H}_{2} \mathrm{O}_{2}$ detection.

Figure 4: ElecFET microsensor response versus time $\left(\mathrm{VP}_{\mathrm{P}}=0.7 \mathrm{~V}\right)$ for the lactate (a) and glucose (b) detection in phosphate buffer solutions

Figure 5: ElecFET lactate (a) and glucose (b) detection for different phosphate buffer concentrations.

Figure 6: ElecFET responses $\Delta \mathrm{V}_{\text {out }}$ versus polarization time tP $\left(\mathrm{V}_{\mathrm{P}}=0.7 \mathrm{~V}\right)$ for lactate (a) and glucose (b) in different buffer concentrations 
a

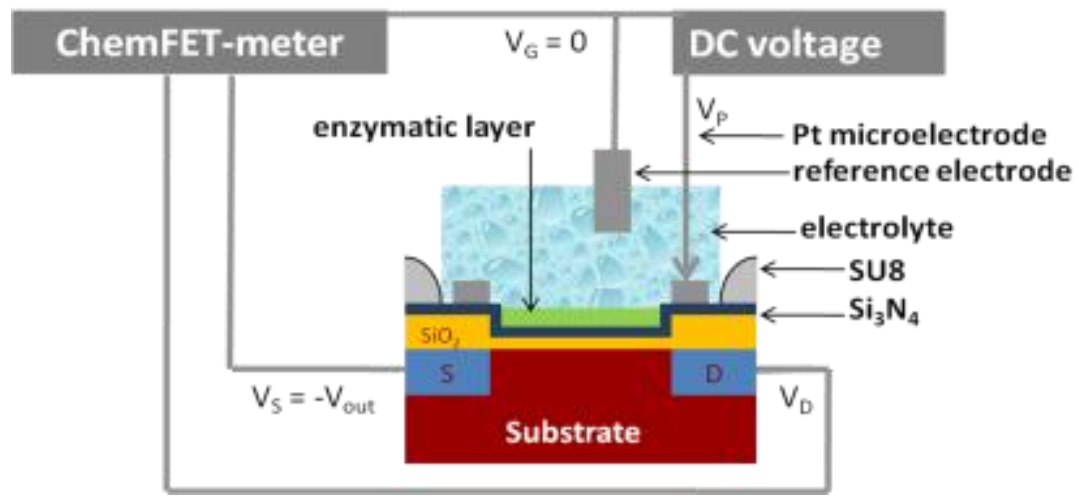

b

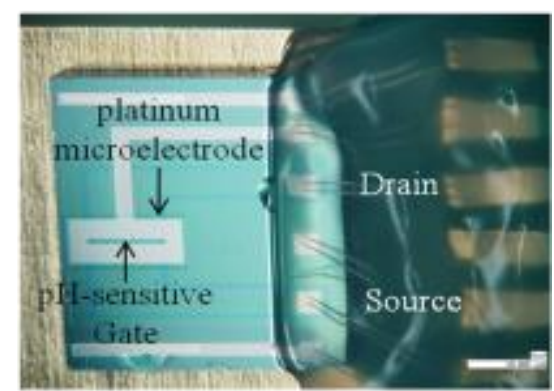

Figure 1: Cross-section (a) and details (b) of the ElecFET device (chip size: $3.5 \times 3.5 \mathrm{~mm}^{2}$ ) 

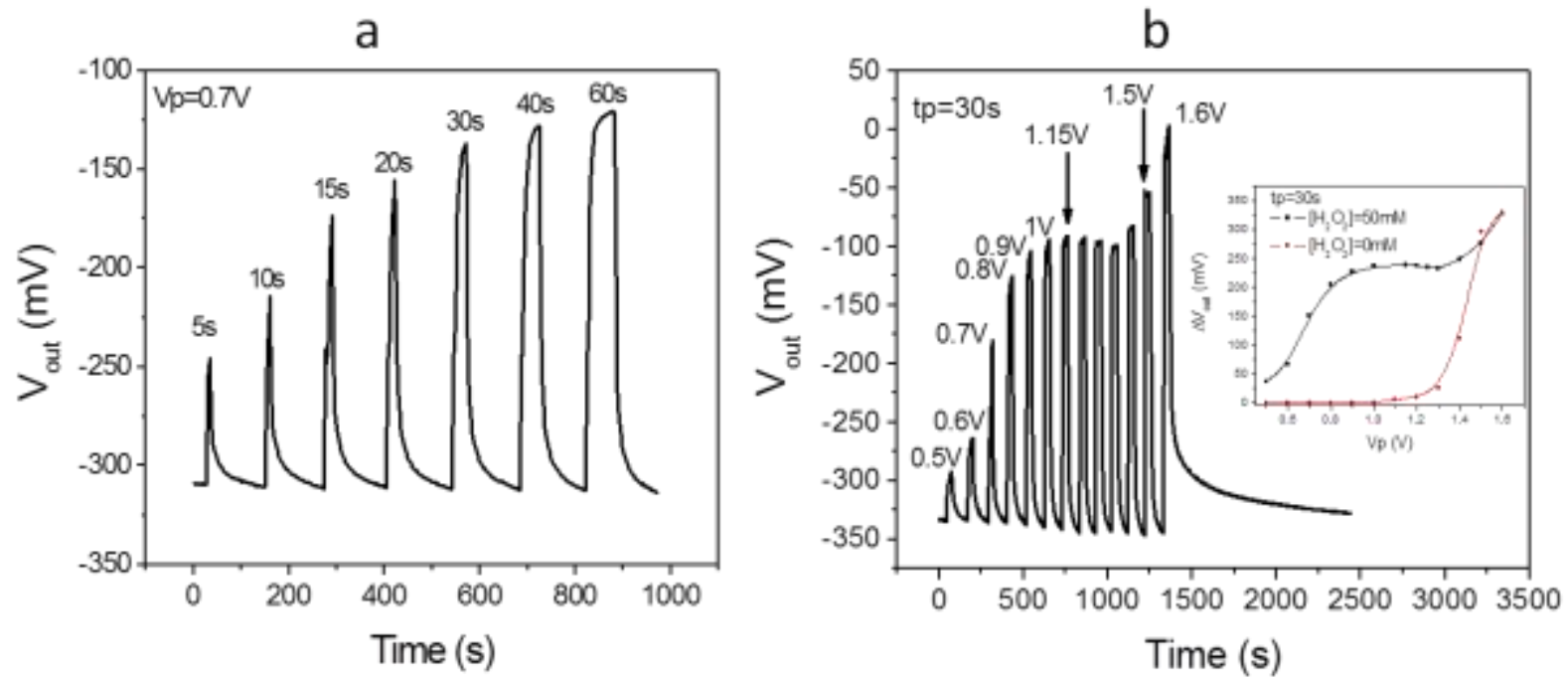

Figure 2: Detection of impulsional $\mathrm{pH}$ variations due to the $\mathrm{H}_{2} \mathrm{O}_{2}$ electrolysis $\left(\left[\mathrm{H}_{2} \mathrm{O}_{2}\right]=50 \mathrm{mM}\right)$ in $100 \mathrm{mM}$ phosphate buffer solutions, influence of the polarization time tp (a) and influence of the polarization voltage $V_{P}$ with and without hydrogen peroxide ( $b$ and inset) 


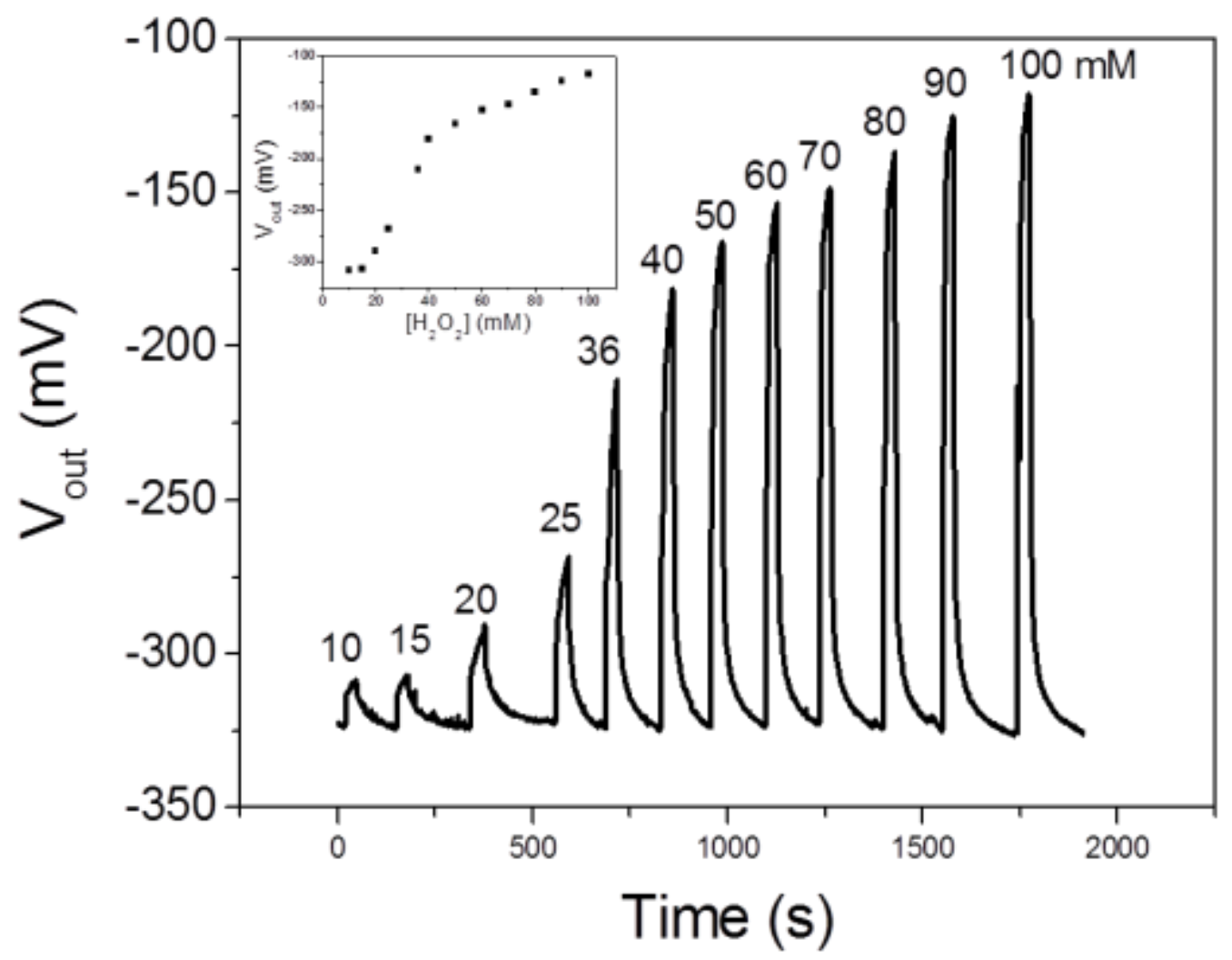

Figure 3: Detection of impulsional $\mathrm{pH}$ variations related to the $\mathrm{H}_{2} \mathrm{O}_{2}$ electrolysis in phosphate buffer solutions: influence of the $\mathrm{H}_{2} \mathrm{O}_{2}$ concentration and (inset) ElecFET response for the $\mathrm{H}_{2} \mathrm{O}_{2}$ detection 

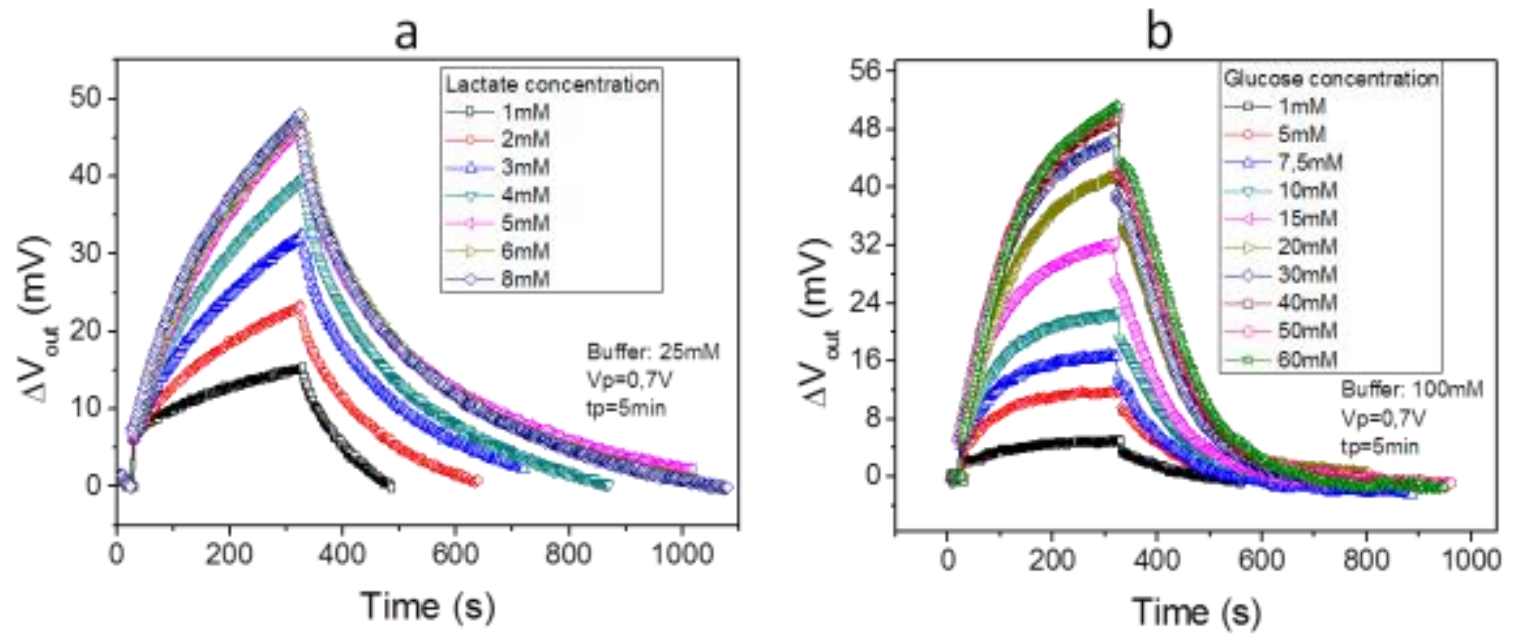

Figure 4: ElecFET microsensor response versus time $\left(V_{P}=0.7 \mathrm{~V}\right)$

for the lactate (a) and glucose (b) detection in phosphate buffer solutions 

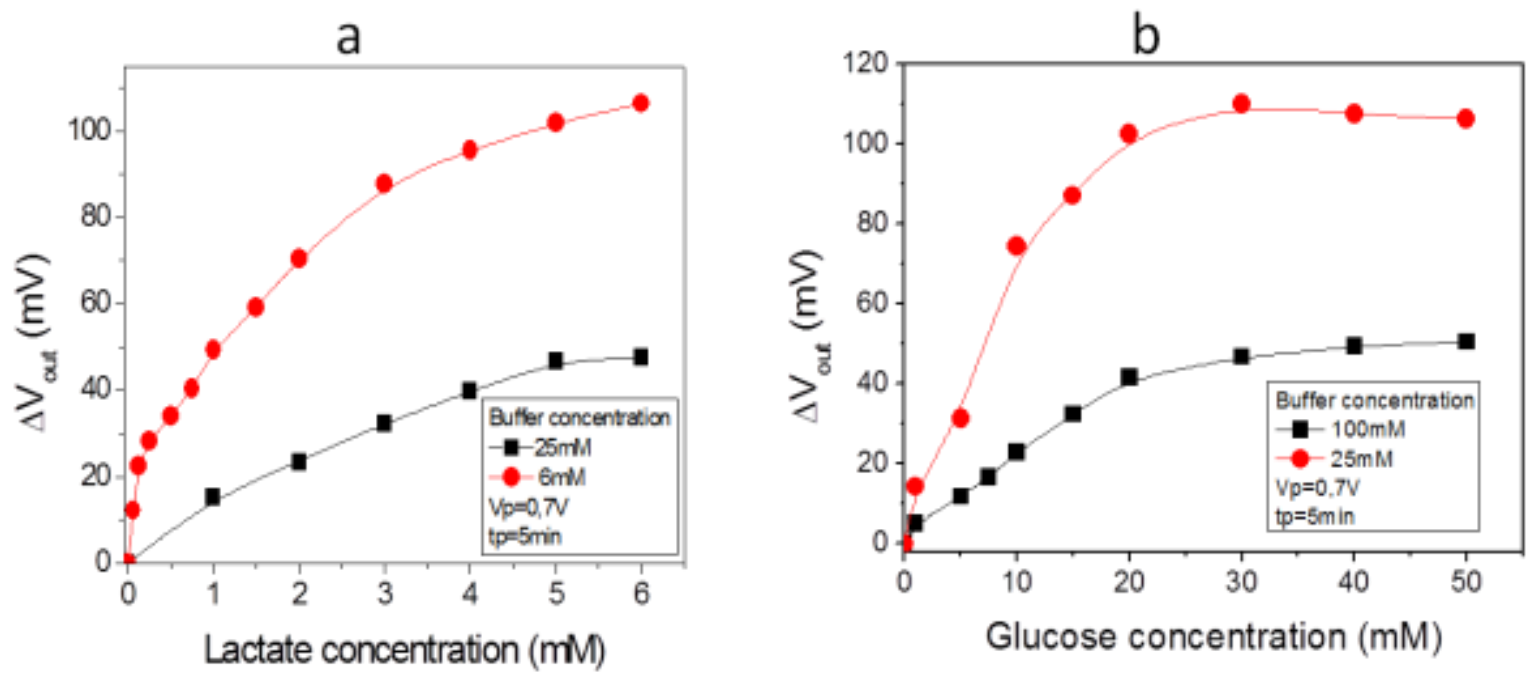

Figure 5: ElecFET lactate (a) and glucose (b) detection for different phosphate buffer concentrations 
a

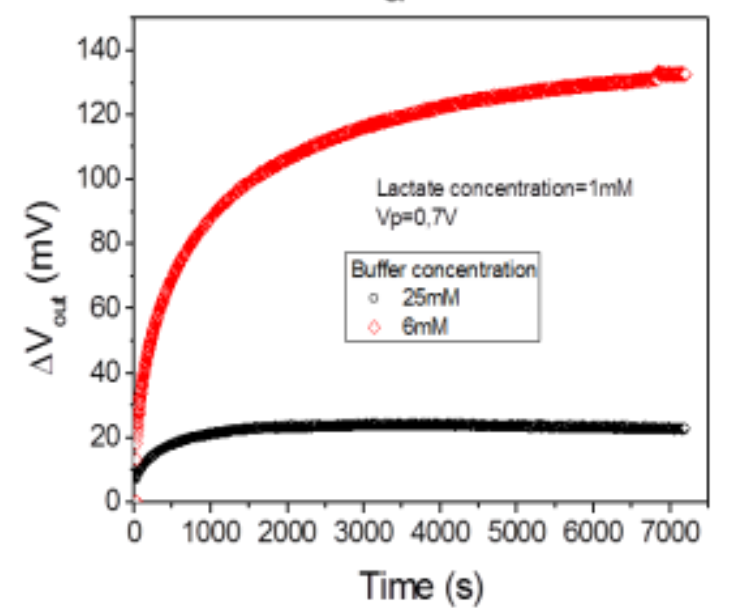

b

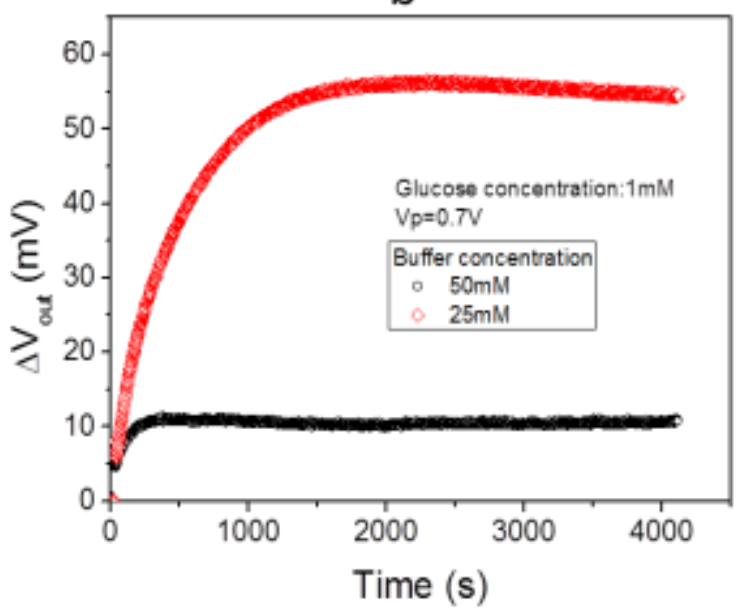

Figure 6: ElecFET responses $\Delta \mathrm{V}_{\text {out }}$ versus polarization time tP $\left(\mathrm{V}_{\mathrm{P}}=0.7 \mathrm{~V}\right)$

for lactate (a) and glucose (b) in different buffer concentrations 